\title{
GERMINAÇÃO DE PHAKOPSORA PACHYRHIZI SID. \& P. SID. SOB DIFERENTES HERBICIDAS
}

\author{
A.V. Schwan-Stoffel ${ }^{1 *}$, W.L. Gavassoni' ${ }^{2}$, L.M.A. Bacchi ${ }^{2}$ \\ ${ }^{1}$ Centro Universitário da Grande Dourados, Faculdade de Ciências Exatas e da Terra, Rua Balbina de Matos, \\ 2121, CEP 79824-900, Dourados, MS, Brasil. E-mail: astoffel@unigran.br
}

\section{RESUMO}

Herbicidas são bastante utilizados na agricultura para controle de plantas daninhas. Por serem aplicados sobre as plantas, além de exercerem ação sobre o organismo alvo, podem influenciar outros processos ou a interação da planta, predispondo ou reduzindo a suscetibilidade a doenças. O efeito dos herbicidas no desenvolvimento de doenças geralmente resulta da ação direta no patógeno e indireta pela ativação de resposta da planta. Objetivou-se neste estudo avaliar in vitro o efeito dos herbicidas cletodim + fenoxaprop-P-etílico, clorimurom-etílico, fomesafem + óleo mineral, lactofem e glyphosate sobre uredósporos de Phakopsora pachyrhizi. A germinação e o comprimento do tubo germinativo dos uredósporos foram avaliados em 1, 2, 4, 8 e 24h de exposição aos herbicidas. Todos os herbicidas inibiram a germinação dos uredósporos. Tubos germinativos emitidos por uredósporos expostos a cletodim + fenoxaprope-P-etílico, clorimurom-etílico, lactofem e glyphosate apresentaram menores comprimentos, indicando ação tóxica dos herbicidas.

PALAVRAS-CHAVE: Ferrugem asiática da soja, uredósporos, controle químico.

\section{ABSTRACT}

THE EFFECT OF HERBICIDES ON THE GERMINATION OF UREDINIOSPORES OF PHAKOPSORA PACHYRHIZI SYD. \& P. SYD. Herbicides are commonly used in agriculture for weed control. Since they are applied in the field, target plants and other organisms are exposed to their action. This exposure may have distinct effects on crop plants, either by predisposing them to plant pathogens or affecting the pathogen's ability to cause disease. The effect of herbicides on the development of disease usually results from direct action on the pathogen and indirectly by the activation of plant response. The objective of this study was evaluate the effect of herbicides, clorimuron-ethyl, fomesafen + mineral oil, cletodim + fenoxaprop-P-ethyl, lactofen on urediniospores of Phakopsora pachyrhizi. Germination and germ tube length were evaluated at the exposure times of 1, 2, 4, 8 and $24 \mathrm{~h}$. All herbicides inhibited urediniospore germination. Chlorimuron-ethyl, cletodim + fenoxaprop-P-ethyl, fomesafen + mineral oil, glyphosate and lactofen reduced germ tube length of urediniospores, indicating that these products were toxic to the spores of P. pachyrhizi.

KEY WORDS: Asian soybean rust, urediniospores, chemical control.

\section{INTRODUÇÃO}

O controle químico de plantas daninhas é uma prática de elevada importância para a obtenção de altos rendimentos das culturas (SILVA; SILVA, 2007). $\mathrm{O}$ efeito dos herbicidas sobre doenças de plantas geralmentenãoé um aspecto considerado no manejo integrado de plantas daninhas. Os herbicidas, por serem aplicados sobre as plantas, além de exercerem ação sobre o organismo alvo, podem influenciar outros organismos. Indiretamente, através dos seus efeitos nas plantas, os herbicidas afetam praticamente todos os processos fisiológicos ou a interação da planta com outros fatores, incluindo sua suscetibilidade a doenças. Em alguns casos, os herbicidas também possuem efeitos diretos em fitopatógenos (ROSA et al., 2010; SOARES et al., 2008; DUKE et al., 2007, WYSS; MÜlLER-SCHÄRER, 2001; SANOGO et al., 2000). Em concentrações subletais ou não tóxicas, os herbicidas podem ter sua influência em doenças de plantas negligenciada (DuKE et al., 2007).

Testes "in vitro" para verificação da ação dos herbicidas glyphosate e halosulfuron sobre o comportamento do crescimento de fitopatógenos revelou

${ }^{2}$ Universidade Federal da Grande Dourados, Faculdade de Ciências Agrárias, Dourados, MS, Brasil.

*Parte da tese do primeiro autor desenvolvida para obtenção do título de Doutor em Agronomia pela Universidade Federal da Grande Dourados, Dourados, MS, Brasil. 
redução no crescimento micelial de Rhizoctonia solani, Ceratocystisfimbriata, Phytophthora capsici, Macrophomina phaseolina, Sclerotium rolfsii, Fusarium oxysporum f.sp. lycopersici e Myrothecium roridum (Rosa et al., 2010). Estes mesmos autores verificaram que o herbicida setoxidim apresentou ação inibitória sobre todos os fungos, exceto sobre Fusarium e Rhizoctonia. SANOGO et al. (2000) reportaram que o glyphosate reduziu a germinação de conídios e o crescimento micelial de Fusarium solani.

WYSS; MÜLLER-SCHÄRER (2001) verificaram a supressão da germinação de aeciósporos de Puccinia lagenophorae quando expostos à dose recomendada a campo de glyphosate e 2,4-D. Um quarto da dose de glyphosate também suprimiu a germinação dos esporos, ao contrário do 2,4-D que ainda permitiu a germinação nos dois experimentos realizados. Os mesmos autores verificaram desenvolvimento anormal do tubo germinativo sob ação de 2,4-D, linuron e glyphosate. Tubos germinativos mostraram-se atrofiados e com menor tamanho em relação à testemunha.

Os herbicidas azafenidin, sulfentrazone eflumioxazin, adicionados em meio de cultura, reduziram o crescimento micelial de Pythium arrhenomanes, $P$. aphanidermatum e P. ultimum. Para P. arrhenomanes, observou-se inibição total do crescimento micelial quando a concentração no meio de cultura era de 1.500 ppm de azafenidin e 750 ppm tanto de sulfentrazone quanto de flumioxazin. Estas concentrações referem-se às doses recomendadas para uso a campo. Mesmo após a diluição de 200 vezes a dose recomendada, detectaram-se reduções de 67, 34 e $36 \%$ no crescimento micelial do patógeno pelos herbicidas azafenidina, flumioxazin e sulfentrazone respectivamente (DAugrois et al., 2005).

O glufosinate aplicado em gramíneas geneticamente modificadas (Agrostis spp.) 3 h antes ou 1 dia após a inoculação de Rhizoctonia solani e Sclerotinia homoeocarpa reduziu a infecção causada por estes fitopatógenos. In vitro a atividade antifúngica do herbicida mostrou inibição completa do crescimento micelial de $R$. solani e $S$. homoeocarpa (WANG et al., 2003).

SOARES et al. (2008) relataram a ação inibitória do glifosato sobre a germinação de uredósporos de Phakopsora pachyrhizi. Entretanto, os autores afirmam que essa ação inibitória não é suficiente para afirmar que o produto é efetivo no controle da ferrugem, quando aplicado em plantas de soja, mas indica atividade fungicida do produto comercial.

Embora o efeito inibitório de herbicidas sobre doenças em várias culturas tenha sido relatado, nem todos os patógenos são afetados de forma semelhante por diferentes herbicidas. Assim, o objetivo deste trabalho foi estudar a germinação de uredósporos de P. pachyrhizi expostos a diferentes herbicidas.

\section{MATERIAL E MÉTODOS}

O trabalho foi realizado nos Laboratórios de Fitopatologia e de Forragicultura da Universidade Federal da Grande Dourados - UFGD, em Dourados, MS. Foram conduzidos dois experimentos para avaliar o efeito de herbicidas na germinação de uredósporos de P. pachyrhizi. Em ambos os experimentos foram utilizados uredósporos coletados de plantas naturalmente infectadas, removidos por meio da agitação manual das folhas sobre uma placa de Petri. No primeiro experimento foram utilizados uredósporos imediatamente após a coleta, e, no segundo, os uredósporos foram armazenados em nitrogênio líquido a $-196^{\circ} \mathrm{C}$. Os esporos foram suspensos em água destilada contendo 1 gota de Tween 20. Utilizou-se $1 \mathrm{~mL}$ de suspensão contendo $1,2.10^{5}$ uredósporos que foram transferidos para placas de Petri contendo agar-água. Em seguida, adicionou-se uma alíquota de $1 \mathrm{~mL}$ de calda de herbicida na suspensão de esporos depositada na placa de Petri, obtendo-se $50 \%$ da concentração do produto comercial recomendado a campo. Os tratamentos utilizados foram: glyphosate dose 475,5 $\mathrm{kg} \mathrm{ha}^{-1}$ i.a., clorimurom-etílico dose $200 \mathrm{~g} \mathrm{ha}^{-1}$ i.a., fomesafem dose $200 \mathrm{~L} \mathrm{ha}^{-1}$ i.a. + óleo mineral dose 0,1 L ha ${ }^{-1}$, cletodim + fenoxaprop-P-etílico dose $50+50 \mathrm{~g} \mathrm{l}^{-1}$ i.a., lactofem dose $180 \mathrm{~L} \mathrm{ha}^{-1}$ i.a. e água como testemunha.

As placas foram incubadas por 1, 2, 4, 8 e $24 \mathrm{~h} \mathrm{em}$ câmara de germinação a $24^{\circ} \mathrm{C}$ sob escuro contínuo. No segundo experimento, a concentração de glyphosate foi aumentada para $576 \mathrm{~kg}$ i.a L-1 ${ }^{-1}$ e a avaliação final realizada após $8 \mathrm{~h}$ de incubação.

Odelineamento experimental utilizado foi inteiramente casualizado, com cinco repetições, sendo cada repetição constituída por uma placa de Petri. Foram utilizadas placas de Petri com $60 \mathrm{~mm}$ de diâmetro e $15 \mathrm{~mm}$ de altura. Decorridos os tempos de exposição aos herbicidas, as placas eram removidas da câmara de incubação e transferidas para refrigerador $\left(5^{\circ} \mathrm{C}\right)$ até a posterior avaliação. Foram quantificados a germinação e o comprimento do tubo germinativo dos uredósporos. Uredósporos foram considerados germinados quando o comprimento do tubo germinativo alcançou o dobro do diâmetro do esporo. Foram observados 50 esporos por placa, aleatoriamente, em microscópio sob aumento de 100 vezes. Cada esporo com tubo germinativo foi fotografado em microscópio óptico e, no segundo experimento, tubos germinativos dos uredósporos foram mensurados para avaliação do comprimento do tubo germinativo e diâmetro do esporo com auxílio do programa Axion Vision 3.1.

A análise estatística dos dados foi feita comauxílio do programa SAS e as médias originais foram comparadas pelo teste de Tukey a $5 \%$ de probabilidade. 


\section{RESULTADOS E DISCUSSÃO}

Houve ação inibitória dos herbicidas sobre $P$. pachyrhizi com redução na germinação de uredósporos nos dois experimentos conforme apresentado na Tabela 1.

Observou-se redução na germinação dos uredósporos de P. pachyrhizi, para todos os herbicidas testados em contraste com a germinação da testemunha. Foram detectadas diferenças na germinação herbicidas e tempos de exposição. No primeiro experimento, com 1 hora de exposição, ocorreu redução de 93,4 \% na germinação de uredósporos sob ação do glyphosate. Os herbicidas lactofem, fomesafem e clorimurom-etílico também inibiram a germinação diferindo-se estatisticamente da testemunha, o índice de redução na germinação foi de 75,83, 65,94 e $61,54 \%$, respectivamente.

Quando os uredósporos foram expostos por 2 horas aos herbicidas, houve redução no índice de germinação dos esporos em todos os tratamentos quando comparados à testemunha. $\mathrm{O}$ maior efeito foi verificado com o herbicida lactofem com redução de $95 \%$ na germinação. Fomesafem, glyphosate e clorimurom-etílico não diferiram significativamente entre si e reduziram a germinação.

Todos os herbicidas testados afetaram a germinação dos esporos após $8 \mathrm{~h}$ de exposição comparados a testemunha. Na avaliação final, após exposição dos uredósporos por $24 \mathrm{~h}$ aos tratamentos, também foi observada a toxicidade dos tratamentos herbicidas, causando inibição de germinação dos esporos. Esporos expostos por $24 \mathrm{~h}$ ao lactofen apresentaram índice germinativo semelhante aos expostos somente a água (testemunha) como também aos demais herbicidas. Neste primeiro experimento, não foi utilizado o tratamento cletodim + fenoxaprop-P-etílico.

No segundo experimento, verificou-se maior redução na germinação dos uredósporos após exposição aos herbicidas glyphosate, cletodim + fenoxaprop-P-etilico e lactofem comparados à testemunha. O índice de redução variou de 31 a $100 \%$ para os herbicidas utilizados. Os tratamentos clorimurom-etílico e fomesafem também afetaram a germinação dos esporos em relação à testemunha.

$\mathrm{Na}$ avaliação final, realizada após $8 \mathrm{~h}$ de exposição aos produtos, observou-se diferença significativa na redução da germinação dos uredósporos nos tratamentos glyphosate e cletodim + fenoxapropP-etílico em relação a testemunha. Todos os demais tratamentos foram iguais entre si e não diferiram significativamente da testemunha.

No primeiro experimento observou-se que, em todas as avaliações, a germinação dos uredósporos de P. pachyrhizi foi menor em todos os tratamentos herbicidas. Entretanto, notratamentolactofem, verificou-se um aumento na germinação de acordo com o tempo de exposição ao produto (Fig. 1). Na avaliação para os diferentes tempos de exposição aos produtos no segundo experimento, observou-sequea germinação dos uredósporos de P. pachyrhizi foi menor em todos os tempos de exposição nos tratamentos glyphosate e cletodim + fenoxaprop-P-etílico. Nos tratamentos fomesafem, clorimurom-etílico elactofem verificou-se um aumento na germinação de acordo com o tempo de exposição aos produtos (Fig. 2).

Tabela 1 - Germinação de uredósporos (\%) de Phakopsora pachyrhizi expostos a diferentes herbicidas e tempos de exposição, nos experimentos I e II. Dourados, MS, 2008/2009.

\begin{tabular}{|c|c|c|c|c|c|c|c|c|c|}
\hline Experimento I & \multicolumn{9}{|c|}{ Germinação (\%) em diferentes tempos de exposição } \\
\hline Tratamentos & \multicolumn{2}{|c|}{$1 \mathrm{~h}$} & \multicolumn{2}{|c|}{$2 \mathrm{~h}$} & \multicolumn{2}{|c|}{$4 \mathrm{~h}$} & \multicolumn{2}{|c|}{$8 \mathrm{~h}$} & $24 \mathrm{~h}$ \\
\hline Glyphosate & 2,4 & $\mathrm{C}$ & 4,4 & $\mathrm{~b}$ & 13,6 & $\mathrm{a}$ & 11,2 & $\mathrm{~b}$ & $1,6 \quad b$ \\
\hline Clorimurom-etílico & 14,0 & $\mathrm{~b}$ & 9,6 & $\mathrm{~b}$ & 15,2 & a & 15,2 & $\mathrm{~b}$ & $3,6 \mathrm{~b}$ \\
\hline Fomesafem $^{1}$ & 12,4 & $\mathrm{~b}$ & 9,2 & $\mathrm{bc}$ & 12,4 & a & 8,4 & $b$ & $4,0 \quad b$ \\
\hline Lactofem & 8,8 & $\mathrm{~b}$ & 2,0 & $c$ & 1,6 & $\mathrm{~b}$ & 9,6 & $\mathrm{~b}$ & $1,2 \mathrm{ab}$ \\
\hline Testemunha & 36,4 & $\mathrm{a}$ & 39,6 & $\mathrm{a}$ & 29,2 & $\mathrm{a}$ & 39,2 & $\mathrm{a}$ & 8,8 a \\
\hline $\mathrm{CV}(\%)$ & 25, & & 27,3 & & 38, & & 31,7 & & 26,5 \\
\hline Experimento II & \multicolumn{9}{|c|}{ Germinação (\%) em diferentes tempos de exposição } \\
\hline Tratamentos & \multicolumn{2}{|c|}{$1 \mathrm{~h}$} & \multicolumn{2}{|c|}{$2 \mathrm{~h}$} & \multicolumn{2}{|c|}{$4 \mathrm{~h}$} & \multicolumn{2}{|c|}{$8 \mathrm{~h}$} & $24 \mathrm{~h}^{2}$ \\
\hline Glyphosate & 0,0 & $\mathrm{C}$ & 0,8 & c & 0,8 & c & 0,4 & $\mathrm{~b}$ & --- \\
\hline Clorimurom-etílico & 13,2 & $\mathrm{bc}$ & 25,6 & $\mathrm{~b}$ & 60,8 & $\mathrm{ab}$ & 82,4 & a & -- \\
\hline Fomesafem $^{1}$ & 32,4 & $\mathrm{~b}$ & 22,4 & $\mathrm{~b}$ & 53,2 & $\mathrm{~b}$ & 81,6 & a & --- \\
\hline Cletodim + fenoxaprop-P-etílico & 0,0 & c & 0,0 & c & 0,4 & c & 2,0 & $\mathrm{~b}$ & --- \\
\hline Lactofem & 1,2 & c & 1,2 & c & 0,4 & c & 63,2 & a & --- \\
\hline Testemunha & 78,4 & $\mathrm{a}$ & 60,8 & $\mathrm{a}$ & 77,6 & $\mathrm{a}$ & 69,2 & $\mathrm{a}$ & --- \\
\hline $\mathrm{CV}(\%)$ & 31 & & 37,0 & & 47 & & 15,9 & & --- \\
\hline
\end{tabular}

Médias seguidas pela mesma letra na coluna não diferem entre si pelo teste de Tukey a $5 \%$ de probabilidade. Para análise estatística, os dados foram transformados em arcoseno raiz de x/100.

${ }^{1}$ Acrescido de óleo mineral 0,5 L $100 \mathrm{~L}^{-1}$ de calda.

${ }^{2}$ Somente foram efetuadas avaliações as $24 \mathrm{~h}$ de exposição no experimento I. 
Rosa et al. (2010) verificaram o efeito fungistático do herbicida setoxidim sobre $P$. capsici. Os autores comprovaram o efeito fungistático do herbicida sobre o crescimento vegetativo submetendo o isolado à exposição ao produto e, posteriormente, transferindo o isolado para meio de cultura BDA sem acréscimo do composto químico. Após a transferência, foi observado o crescimento normal da cultura. DANN et al. (1999) verificaram que o herbicida lactofem reduziu indiretamente a severidade da podridão da haste da soja. Os autores descartaram a possibilidade de ocorrência de efeito direto devido ao fato do herbicida ser facilmente degradado em condições aeróbias com meia vida de três dias. RoDRIGUES; ALMEIDA (2011) descreveram os herbicidas fomesafem e clorimurom-etílico com baixa volatilização e baixa degradação. A natureza da inibição da germinação dos uredósporos, fungistática ou fungicida não pode ser determinada no presente trabalho, considerando a persistência dos herbicidas no meio e pela impossibilidade de transferência dos uredósporos para substrato livre de herbicida.

SOARES et al. (2008) observaram o efeito supressivo do herbicida glyphosate sobre a germinação de esporos de $P$. pachyrhizi em condições controladas. A aplicação do glyphosate foi realizada em plantas, em casa de vegetação, e o efeito do produto sobre a ferrugem ocorreu preventivamente, porém, com limitado período de proteção na planta. Para os autores, quando os primeiros esporos do fungo são depositados sobre as folhas, têm a germinação inibida pelo contato com o produto, porém, considerando-se a característica policíclica e a alta produção de inoculo da ferrugem que geram frequentes deposições de esporos nas plantas, o curto período de proteção do glyphosate não seria suficiente para suprimir infecções que ocorram em períodos subsequentes à aplicação do herbicida.

A germinação dos esporos variou nos dois experimentos e foi maior no segundo experimento. Fato semelhante foi encontrado no trabalho de WYSS; MÜLLER-SCHÄRER (2001). Os autores verificaram diferença na germinação de aeciosporos de Puccinia lagenophorae, agente de biocontrole da planta Senecio vulgaris em dois experimentos realizados. De acordo com os autores, a maturidade dos aeciosporos, dormência constitutiva e o método de armazenamento dos esporos podem ter influenciado a germinação e a qualidade dos esporos. No presente trabalho, foram utilizados uredósporos coletados de plantas naturalmente infectadas. As folhas foram agitadas manualmente para liberação dos uredósporos maduros, minimizando-se assim a possibilidade da imaturidade dos esporos ter causado diferença na germinação entre os experimentos. Com relação ao método de armazenamento, para o segundo experimento, os uredósporos foram coletados e armazenados em nitrogênio líquido até a instalação do trabalho, nota-se que este experimento teve uma germinação maior que o primeiro.

A concentração de glyphosate utilizado no experimento foi de $475,5 \mathrm{~kg}$ i.a kg-1 . No segundo experimento utilizou-se a concentração de $576 \mathrm{~kg}$ i.a $\mathrm{L}^{-1}$. Entretanto, observa-se que nos dois experimentos realizados a exposição dos uredósporos à metade da dose recomendada de glyphosate foi suficiente para afetar a germinação dos uredósporos, indicando quea diferença na concentração entre os dois experimentos não interferiu na toxidez aos esporos.

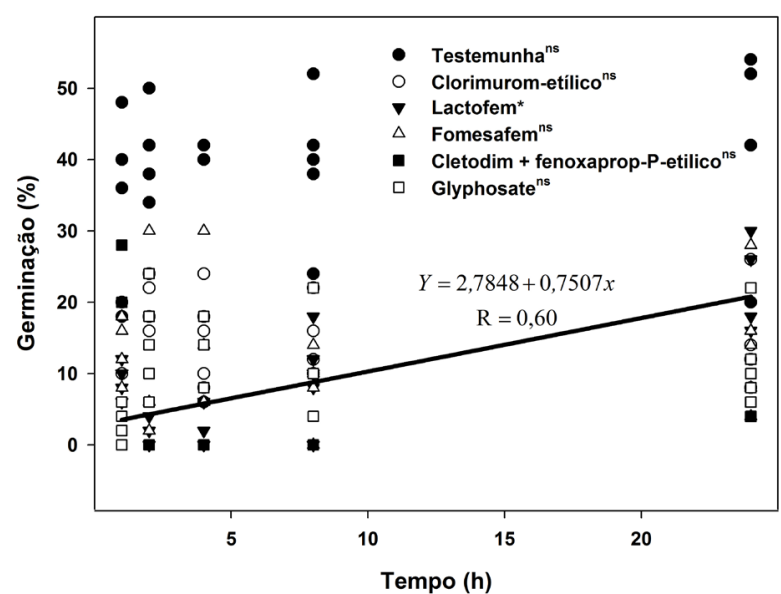

Fig.1-Germinação de uredósporos de Phakopsora pachyrhizi em diferentes tempos de exposição aos herbicidas cletodim + fenoxaprop-P-etílico, clorimuron-etílico, fomesafem, lactofem (-) e testemunha.

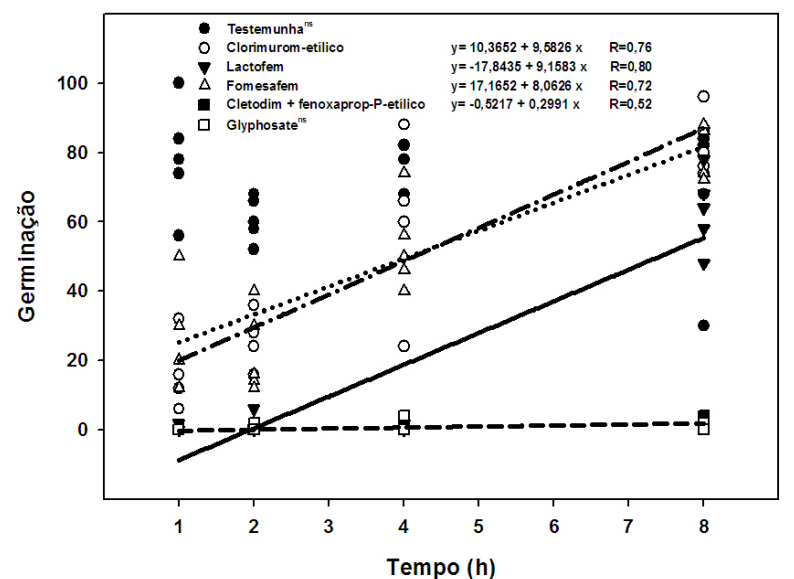

Fig. 2-Germinação de uredósporos de Phakopsora pachyrhizi em diferentes tempos de exposição aos herbicidas cleto$\mathrm{dim}+$ fenoxaprop-P-etílico (- - -), clorimuron-etílico (- ${ }^{\mathrm{n}}$ - ), fomesafem (․), lactofem (-) e testemunha. 
WYSS; MÜLLER-SCHÄRER (2001) verificaram que a aplicação de glyphosate na dose recomendada a campo, 2,5 L ha-1 ${ }^{-1}$, suprimiu a germinação de esporos de Puccinia lagenophorae. O mesmo trabalho relata que a adição de menores doses, 0,62, 0,031 e 0,062 L ha $^{-1}$ em meio de cultura inibiu significativamente a germinação de esporos do fungo. Acredita-se que o efeito inibitório do glyphosate sobre o crescimento de alguns fitopatógenos esteja relacionado à inibição da enzima 5-enolpiruvilshiquimato-3-fosfato sintase (EPSPs) importante na produção de aminoácidos aromáticos na rota do ácido shiquímico (DuKE et al., 2003). Os aminoácidos são essenciais no crescimento e desenvolvimento dos fungos por estarem envolvidos na síntese de proteínas. Cletodim + fenoxaprop-P-etílico apresentou ação inibitória sobre a germinação dos uredósporos de P.pachyrhizi, possivelmente a ação do herbicida sobre o patógeno tenha ocorrido devido a inibição da enzima Acetil CoA Carboxilase (ACCase) responsável pela biossíntese dos ácidos graxos, constituintes básicos da membrana celular, causando a inibição da divisão celular do fungo.

FENG et al. (2005) verificaram a campo o efeito preventivo e curativo de baixas concentrações de glyphosate sobre Puccinia striiformis f.sp. tritici e $P$. triticina, patógenos que causam a ferrugem estriada e ferrugem da folha, respectivamente, na cultura do trigo. Para os autores, a atividade do glyphosate se dá pela inibição da EPSPS do fungo, o mesmo mecanismo atribuído à atividade herbicida. Assim, quando ocorre a deposição dos uredósporos na planta e, posteriormente, a infecção, ocorre a exposição ao glyphosate.

Rosaetal. (2010), em testes in vitro para verificação da ação de herbicidas sobre o comportamento decrescimento de fitopatógenos, também demonstraram a ação fungicida do herbicida glyphosate ao fungo $P$. capsici, apresentando efeito supressor ao crescimento micelial. Os autores comentam que a proximidade evolucionária dos oomycotas com vegetais superiores tornam esse grupo mais vulnerável à ação do herbicida glyphosate.
SANOGO et al. (2000) observaram redução de 94 a $98 \%$ na germinação de conídios de três isolados de Fusarium solani f. sp. glycines quando expostos ao herbicida glyphosate na concentração recomendada a campo. Os mesmos autores observaram que, quando os conídios foram expostos a imazethapyr e lactofen, a germinação foi reduzida em somente 8 a $48 \%$. Neste trabalho, os herbicidas lactofem e fomesafem, pertencentes ao grupo dos inibidores de protoporphyrinogen oxidase e utilizados na metade da dose recomendada a campo, apresentaram ação tóxica a uredósporos de P. pachyrhizi, porém, a inibição dos esporos foi reduzida com o aumento no tempo de exposição.

Para o comprimento do tubo germinativo (Tabela 2) observou-se, na primeira avaliação, redução no comprimento dotudo germinativo quando osesporos ficaram expostos aos herbicidas glyphosate, cletodim + fenoxaprope-P-etílico, lactofem eclorimurom-etílico. Não foi verificada diferença significativa entre os tratamentos fomesafem e testemunha. Nas avaliações seguintes, os tratamentos clorimurom-etílico, fomesafem e a testemunha não diferiram entre si significativamente, indicando uma limitação desses produtos ao tempo de exposição dos uredósporos. Na avaliação realizada duas horas após exposição aos produtos, foi observada emissão de tubo germinativo dos uredosporos, diferindo das demais avaliações.

A ação de herbicidas sobre o crescimento vegetativo de alguns patógenos foi relatada (DAugroIs et al., 2005; Nemoto et al., 2002). Daugrois et al. (2005), trabalhando com fitopatógenos do reino Stramenopila, verificou que baixas concentrações $18,7,15$ e $10 \mathrm{mg} \mathrm{L}^{-1}$ respectivamente dos herbicidas azafenidin, flumioxazin e sulfentrazone reduziram "in vitro" o crescimento micelial de P. arrhenomanes, P. aphanidermatume P. ultimum. No presente trabalho foram utilizados os herbicidas fomesafem e lactofem pertencentes ao mesmo grupo, inibidores de protoporphyrinogen oxidase, verificando-se que o lactofem afetou o crescimento do tubo germinativo de P.pachyrhizi em todas as avaliações, enquanto que o fomesafem só afetou após exposição de 4 horas.

Tabela 2 - Comprimento do tubo germinativo de uredósporos de Phakopsora pachyrhizi expostos a herbicidas. Dourados, MS, 2009.

\begin{tabular}{|c|c|c|c|c|}
\hline \multicolumn{5}{|c|}{ Comprimento do tubo germinativo $(\mu \mathrm{m})$ em diferentes tempos de exposição ${ }^{1}$} \\
\hline Tratamentos & $1 \mathrm{~h}$ & $2 \mathrm{~h}$ & $4 \mathrm{~h}$ & $8 \mathrm{~h}$ \\
\hline Glyphosate & $0,0 \mathrm{~b}$ & $26,4 \mathrm{~b}$ & $0,0 \quad \mathrm{c}$ & $0,0 \mathrm{C}$ \\
\hline Clorimurom-etílico & $73,9 \mathrm{~b}$ & 93,0 a & 24,7 & $236,0 \mathrm{a}$ \\
\hline Fomesafem $^{2}$ & $98,0 \mathrm{a}$ & $72,7 \mathrm{a}$ & 20,2 & $194,9 \mathrm{a}$ \\
\hline Cletodim + fenoxaprope-P-etílico & $0,0 \mathrm{~b}$ & $0,0 \mathrm{~b}$ & 0,0 & $0,0 \mathrm{c}$ \\
\hline Lactofem & $0,0 \mathrm{~b}$ & $0,0 \mathrm{~b}$ & 28,0 & $80,2 \mathrm{~b}$ \\
\hline Testemunha & 129,3 a & 128,7 a & 141,0 a & $193,8 \mathrm{a}$ \\
\hline $\mathrm{CV}(\%)$ & 31,0 & 37,0 & 48,0 & 15,9 \\
\hline
\end{tabular}

Médias seguidas pela mesma letra na coluna não diferem entre si pelo teste de Tukey a 5\% de probabilidade.

${ }^{1}$ Médias obtidas de da mensuração de 50 esporos. Para análise estatística, os dados foram transformados em raiz de $\mathrm{x}$.

${ }^{2}$ Acrescido de óleo mineral 0,5 L $100 \mathrm{~L}^{-1}$ de calda. 
A

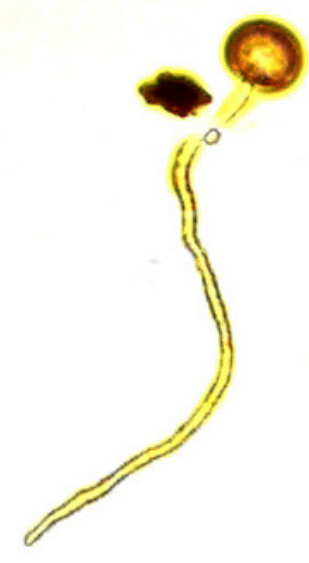

B

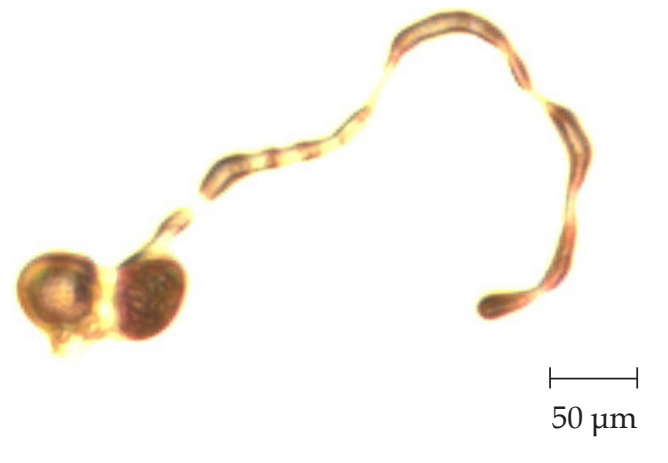

Fig. 3 - Uredósporos com emissão de tubo germinativo emitido no tratamento testemunha (A). Uredósporos com emissão de tubo germinativo deformado após exposição aos herbicidas (B).

O crescimento micelial de Bipolaris euphorbiae foi levemente afetado por oxasulfuron e mostrou-se insensível a bentazon e fomesafen. Porém, glyphosate, chorimuron-ethyl e lactofen o reduziram expressivamente. Entre estes herbicidas, foi observada que apenas na presença de glyphosate a tendência de germinação dos conídios diferiu da observada com água (Nемото et al., 2002).

Diferentes substâncias químicas fazem parte da formulação dos herbicidas, como solventes, surfactantes e agentes molhantes. Tais substâncias podem potencializar os efeitos negativos dos herbicidas em organismos (MALKONES, 2000), porém, não foram testadas neste trabalho. De acordo com STEINER; WATSON (1965), os surfactantes podem conter mais de quinze moléculas de óxido de etileno. Assim, não se pode afirmar qual componente específico da formulação dos produtos exerceu a inibição constatada. Em caso de herbicidas que favoreçam um claro efeito fungicida sobre patógenos importantes como P.pachyrhizi, a investigação do componente que exerceu o efeito deveria ser realizada.

A germinação dos uredósporos foi afetada por todos os herbicidas. Além disso, os uredósporos que chegaram a emitir o tubo germinativo apresentaramnocomaspecto deformado, com anelações (alterações no diâmetro do tubo germinativo) eáreas com maior concentração citoplasmática que outras (Fig. 3).

WYSS; MÜLLER-SCHÄRER (2001) observaram redução significativa da formação do peg de penetração de aeciosporos de $P$. lagenophorae, após exposição ao herbicida Linuron em relação à água. Neste trabalho, as avaliações foram limitadas à ação dos herbicidas sobre a germinação dos uredósporos, porém, considerando a estabilidade dos herbicidas nos tecidos vegetais, futuros trabalhos deveriam investigar a ação dos herbicidas sobre a infectividade de P. pachyrhizi.

\section{CONCLUSÕES}

Os herbicidas glyphosate, clorimurom-etílico, fomesafem + óleo mineral, cletodim + fenoxapropP-etílico e lactofem, nas doses utilizadas, possuem efeito inibidor da germinação de uredósporos de P. pachyrhizi.

Glyphosate, clorimurom-etílico, cletodim + fenoxaprop-P-etílico e lactofem são tóxicos a uredósporos de P. pachyrhizi prejudicando o desenvolvimento e a integridade do tubo germinativo.

\section{AGRADECIMENTOS}

À Coordenação de Aperfeiçoamento dePessoal de Nível Superior (CAPES) pela concessão de bolsa de doutoradoà primeira autora. À Fazenda Paquetá pela doação dos herbicidas. À professora Beatriz Lempp pela disponibilização dos equipamentos fotográficos.

\section{REFERÊNCIAS}

DANN, E.K.; DIERS, B.W.; HAMMERSCHMIDT, R. Suppression of Sclerotinia stem rot of soybean by lactofen herbicide treatment. Phytopathology, v.89, n.7, p.598-602, 1999.

DAUGROIS, J.H.; HOY, J.W.; GRIFFIN, J.L. Protoporphyrinogen oxidase inhibitor herbicide effects on 
Pythium root rot of sugarcane, Pythium species, and the soil microbial community. Phytopathology, v.95, n.2, p.220-226, 2005.

DUKE, S.O.; RIMANDO, A. M.; PACE, P.F.; REDDY, K.N.; SMEDA, R. J. Isoflavone, glyphosate, and aminomethylphosphonic acid levels in seeds of glyphosate-treated soybean. Journal of Agricultural and Food Chemistry, v.51, n.5, p.340-344, 2003.

DUKE, S.O.; CERDEIRA, A.L.; MATALLO, M.B. Herbicide effects on plant disease. Outlooks on Pest Management, v.18, n.1, p.36-40, 2007.

FENG, P.C.C.; JAMES BALE, G.; CLINTON, W.P.; BUNKERS, G.J.; ALIBHAI, M.F.; PAULITZ, T.C.; KIDWELL, K.K. Glyphosate inhibits rust diseases in glyphosate-resistant wheat and soybean. Proceedings of the National Academy of Sciences of the United States of America, v.102, n.48, p.17290-17295, 2005.

MALKONES, H.P. Comparison of the effects of differently formulated herbicides on soil microbial activities - a review. Jounal of Plant Disease and Protection, v.8, p.781-789, 2000.

NEMOTO, M.C.M.; NAHAS, E.; PITELLI, R.A.; COELHO, L. Germination and mycelial growth of Bipolaris euphorbiae Muchovej \& Carvalho as influenced by herbicides and surfactants. Brazilian Journal of Microbiology, v.33, n.4, p.352-357, 2002.

RODRIGUES, B.N.; ALMEIDA, F.L.S. de (Ed.). Guia de herbicidas. 6.ed. Londrina: IAPAR, 2011. 697p.

ROSA, D.D.; BASSETO, M.A.; CAVARIANI, C.; FURTADO, E.L. Efeito de herbicidas sobre agentes fitopato- gênicos. Acta Scientiarum Agronomy, v.32, n.3, p.379-383, 2010.

SANOGO, S.; YANG, X.B.; SCHERM, H. Effects of herbicides on Fusarium solani f.sp. glycines and development of sudden death syndrome in glyphosate-tolerant soybean. Phytopathology, v.90, n.1, p.57-66, 2000.

SILVA, A.A. da; SILVA, F.J. da Tópicos em manejo de plantas daninhas. Viçosa: Ed. UFV, 2007. 367p.

SOARES, R.M.; GAZZIERO, D.L.P.; MORITA, D.A.S. dos; CILIATO, M.L.; FLAUSINO, A.M.; SANTOS,

L.C.M.; JANEGITZ, T. Utilização de glyphosate para o controle de ferrugem da soja. Pesquisa Agropecuária Brasileira, v.43, n.4, p.473-477, 2008.

STEINER, G.W.; WATSON, R.D. The effect of surfactants on growth of fungi. Phytopathology, v.55, p.10091012, 1965.

WANG, Y.; BROWNING, M.; RUEMTNELE, B.A.; CHANDLEE, J.M.; KAUSCH, A.P.; JACKSON, N. Glufosinate reduces fungal diseases in transgenic glufosinate-resistant bentgrasses (Agrostis spp.). Weed Science, v.51, n.1, p.130-137, 2003.

WYSS, G.S.; MÜLLER-SCHÄRER, H. Effects of selected Herbicides on the germination and infection process of Puccinia lagenophora, a biocontrol pathogen of Senecio vulgaris. Biological Control, v.20, n.1, p.160-166, 2001.

Recebido em $12 / 7 / 11$

Aceito em 3/7/12 